\title{
SRS Basins Report
}

\author{
Layne Pincock
}

May 2017

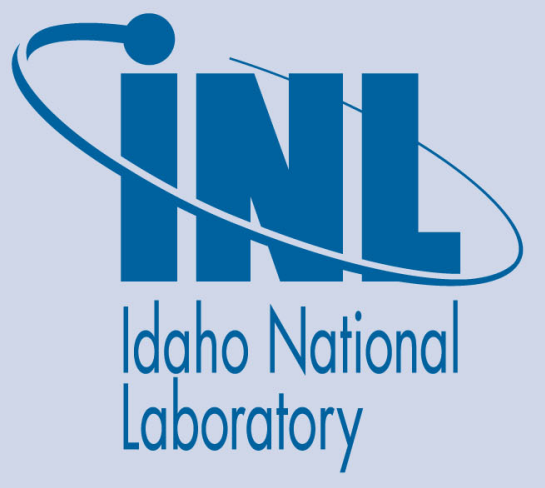

The INL is a U.S. Department of Energy National Laboratory operated by Battelle Energy Alliance 


\title{
SRS Basins Report
}

\author{
Layne Pincock
}

May 2017

\section{Idaho National Laboratory Idaho Falls, Idaho 83415}

http://www.inl.gov

Prepared for the U.S. Department of Energy Office of Environmental Management Under DOE Idaho Operations Office Contract DE-AC07-05ID14517 
Breakdown of spent fuel in SRS Basins

\begin{tabular}{l|c|c|c|}
\multicolumn{1}{c}{ MTHM } & \multicolumn{1}{c}{ \# of Assemblies/Items } & Volume $\left(\mathrm{m}^{3}\right)$ \\
\cline { 2 - 4 } DOE Legacy* & 24.1 & 4,745 & 34.9 \\
\cline { 2 - 4 } DRR \& FRR & 5.37 & 9,403 & 42.6 \\
\hline
\end{tabular}

2011

DOE Legacy*

DRR \& FRR

MTHM \# of Assemblies/Items Volume

\section{MTHM}
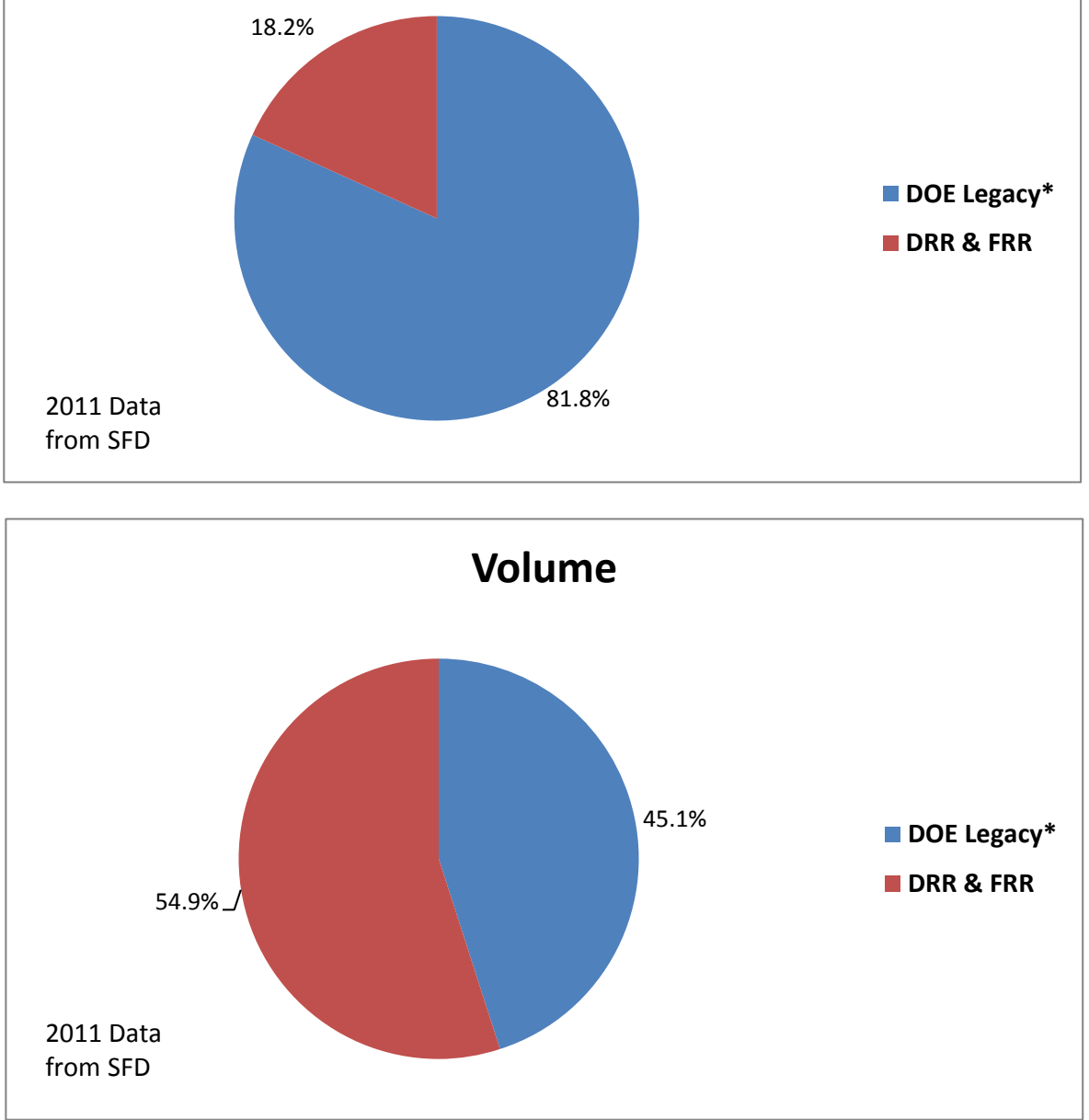

*DOE Legacy consists of DOE research fuels, defense related fuels, commercial fuels in DOE custody, and other non-aluminum fuels

**Based on presentation given by Dawn Gillas, Used Nuclear Fuel Program Manager, DOE-SR, July 2011

Note: Assemblies/Items refers to fuel units in the Spent Fuel Database (SFD). Fuel units could be assemblies, rods, elements, canisters, bundles, or plates.
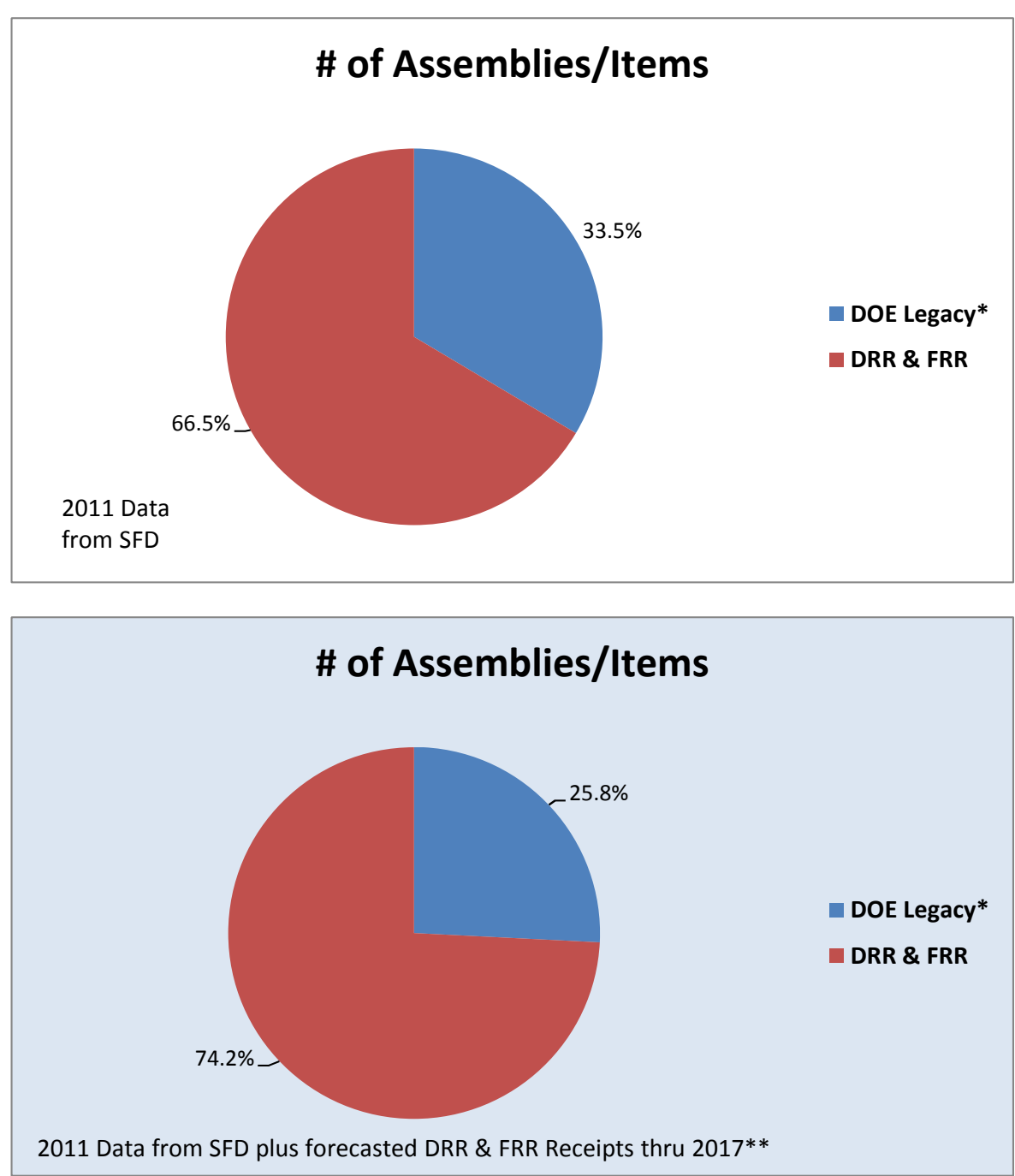

\begin{tabular}{r|c|}
2017 Estimate \# of Assemblies/Items \\
\cline { 2 - 2 } DOE Legacy* & $\mathbf{2 5 . 8 \%}$ \\
& $\mathbf{7 4 . 2 \%}$ \\
\hline DRR \& FRR &
\end{tabular}

